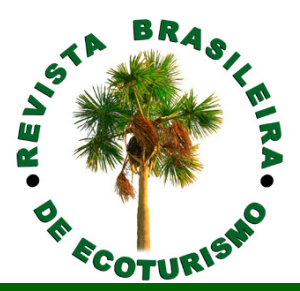

\title{
Acessibilidade no Ecoturismo e Turismo de Aventura: atuação do poder público e privado ${ }^{1}$
}

\author{
Accessibility in Ecotourism and Adventure Tourism: \\ the role of the government and private companies
}

Grislayne Guedes Lopes da Silva, Reinaldo Miranda de Sá Teles

\begin{abstract}
RESUMO
O presente artigo tem como principal objetivo averiguar como as empresas de Ecoturismo e Turismo de Aventura percebem a atuação do poder público e do privado em ações direcionadas para a acessibilidade. Considerando que o objeto de estudo é a acessibilidade, no decorrer da pesquisa buscouse compreender como questões relacionadas a esse tema são percebidas pelos empreendedores; se o mercado está se adequando para receber esse perfil de público com deficiência ou mobilidade reduzida; e se há demonstração de interesse em tornar atividades acessíveis para essa demanda crescente. Os principais resultados do estudo demonstram que a maioria das empresas não estão preparadas para atender esse público, porém apontam direções que visam a melhoria no atendimento do público em questão e a qualidade da oferta de Ecoturismo e Turismo de Aventura no quesito acessibilidade.
\end{abstract}

PALAVRAS-CHAVE: Poder Público; Poder Privado; Acessibilidade; Pesquisa Qualitativa.

\section{ABSTRACT}

The main objective of this article is to ascertain how Ecotourism and Adventure Tourism companies perceive the role of the government and private companies in activities related to accessibility. Whereas the focus of this study is accessibility, during the research phase it was sought to understand how issues related to this topic are perceived by entrepreneurs, if the market is adapting to be able to accommodate persons with disabilities or reduced mobility, and any interest has been demonstrated in making activities accessible in light of this growing demand. The main results of the study show that most companies are not prepared to accommodate this segment of the population; however, suggestions are made for improving their ability to meet the needs of this public, as well as the quality of Ecotourism and Adventure Tourism services in terms of accessibility.

KEYWORDS: Government; Private companies; Accessibility; Qualitative research. 


\section{Introdução}

No intuito de melhor entender o objeto dessa pesquisa, este artigo discute a atuação do poder público como ator importante no desenvolvimento de políticas públicas em acessibilidade e no incentivo às empresas para desenvolvimento de atividades para o público com deficiência ou mobilidade reduzida, tendo como recorte os segmentos de ecoturismo e turismo de aventura. Considerando a escassez de pesquisas acadêmicas relacionadas ao tema acessibilidade nesses segmentos, buscou-se também discutir e refletir sobre a atuação do poder privado no mercado estudado, observando-se questões relacionadas à acessibilidade, à inclusão social e à oportunidade de negócio para as empresas.

Este artigo teve como principal objetivo averiguar junto a algumas empresas dos segmentos estudados se há preparo e interesse para atender o público com deficiência ou mobilidade reduzida (tratado neste estudo como público especial), bem como se já existem produtos e atividades ofertadas por estas empresas que atendam às necessidades e anseios do público especial. Também se analisou a percepção dos empresários sobre a atuação do poder público no que diz respeito à elaboração de políticas voltadas à acessibilidade no turismo.

Para a elaboração dessa pesquisa, a busca pelo público usuário de serviços turísticos e empreendedores entendidos como público alvo de investigação, assim como, os conceitos em torno da acessibilidade e qual é o tipo de legislação específica encontrada sobre os assuntos abordados, constituíram o tripé que promoveu ações de ordem metodológica para melhor apresentação dos resultados da pesquisa.

Nesse sentido, optou-se por apresentar no próximo tópico a trajetória metodológica. E em um segundo momento será dada ênfase à análise dos dados da pesquisa realizada.

\section{Metodologia}

Os procedimentos metodológicos do presente estudo estão divididos em três etapas de trabalho. Em um primeiro momento foi realizada uma pesquisa bibliográfica que incluiu um levantamento de ordem geral envolvendo questões conceituais da área de estudo e, também um levantamento mais específico envolvendo os temas de acessibilidade, normas e legislações, e o mercado de ecoturismo e turismo de aventura. Ao final do levantamento bibliográfico foi possível construir o embasamento para a elaboração do instrumento de pesquisa desse estudo.

$\mathrm{Na}$ segunda parte foram eleitas as empresas a serem entrevistadas no decorrer da pesquisa, as quais foram selecionadas dentro de um conjunto de empresas atuantes nos segmentos de ecoturismo e turismo de aventura. Nesse sentido foram selecionados como universo da pesquisa os membros da Associação Brasileira das Empresas de Ecoturismo e Turismo de aventura (ABETA $)^{2}$, uma vez que a associação apresenta relevante influência e dita tendências no mercado. 
De acordo com o levantamento bibliográfico foi possível inferir que a ABETA é uma das únicas organizações dos segmentos abordados que desenvolve ações em parceria com o Ministério do Turismo para fortalecimento de seus associados no setor. Nesse segundo momento, também foi realizada informalmente uma entrevista com um consultor de acessibilidade no turismo, o que também contribuiu para a discussão e reflexão sobre os assuntos abordados nesse estudo.

$\mathrm{Na}$ terceira etapa de trabalho, as informações foram delineadas com base nos resultados obtidos em pesquisa qualitativa, por meio da aplicação de questionário, com questões fechadas e abertas, enviado via web para 203 associados da ABETA selecionados para compor a amostra. A partir desse universo da pesquisa, obteve-se de retorno 47 questionários preenchidos, o que equivale a $23 \%$ dos associados da ABETA. Considerouse o retorno válido pelo caráter qualitativo da pesquisa, com uma amostra representativa, e a partir disso são apresentados, por meio de uma análise qualitativa, os resultados obtidos no estudo.

\section{Conceituação da área de estudo}

Segundo a Organização das Nações Unidas (ONU), há cerca de 650 milhões de pessoas com deficiência no mundo, o que representa $10 \%$ da população mundial e $80 \%$ vivem em países em desenvolvimento (ONU, 2014). No Brasil, de acordo com o censo IBGE (2010), cerca de 45,6 milhões de pessoas se declararam com alguma deficiência, o que equivale a $23,9 \%$ da população (18,8\% visual, $7 \%$ motora, 5,1\% auditiva e $1,4 \%$ mental ou intelectual).

Para a terminologia, quando se trata de deficiência, podem ser encontrados diversos termos, tais como "deficiente", "pessoa com deficiência", "pessoa portadora de necessidades especiais", "pessoa portadora de deficiência" entre outros. Segundo Sassaki (apud VIVARTA, 2003), a evolução dos termos utilizados ao longo da história para denominar as pessoas com deficiência demonstra grande variedade.

No contexto brasileiro Os inválidos foi um termo bastante utilizado nos romances, nos nomes das instituições e nas leis (Decreto Federal no 60.501, de 14/03/67, dando nova redação ao Decreto nํ 48.959- A, de 19/09/60). Até a década de 1960, a imprensa empregava o termo os incapacitados; da década de 1960 a 1980 utilizava-se os defeituosos, os deficientes, os excepcionais (ARIAS, 2008 p.30). Estes termos são marcos de discussões históricas sobre o uso mais "correto".

No Brasil, utiliza-se desde a década de 1980 o termo "portador de deficiência" na legislação e comunicação, porém, segundo Sassaki (apud VIVARTA, 2003), o termo não é adequado, pois a pessoa não porta a deficiência e sim é uma condição. Dessa forma, por não haver grande consenso, neste estudo é utilizado o termo "pessoa com deficiência" que foi definido na Convenção da Organização das Nações Unidas sobre os Direitos das Pessoas com Deficiência, em 2006, para uso em todos os idiomas. A terminologia "público especial" é um termo um pouco mais abrangente utilizado para caracterizar a pessoa com deficiência ou 
mobilidade reduzida (MOREIRA, 2010) e que é também utilizado nesse estudo.

Segundo a NBR 9050 (ABNT, 2004), o termo acessibilidade se refere a "possibilidade e condição de alcance, percepção e entendimento para a utilização com segurança e autonomia de edificações, espaço, mobiliário, equipamento urbano e elementos ${ }^{3 " .}$. A Norma determina que o termo acessível seja relacionado ao local e elemento "que possa ser alcançado, acionado, utilizado e vivenciado por qualquer pessoa, inclusive aquelas com mobilidade reduzida". E não significa apenas uma acessibilidade física, mas também de comunicação.

Nos segmentos de Ecoturismo e Turismo de Aventura é extremamente importante que a acessibilidade esteja presente nos produtos, seja em equipamentos, serviços, e inclusive nos procedimentos operacionais. As empresas de ecoturismo e turismo de aventura têm a oportunidade de atingir um público em crescimento no mercado, com um diferencial de inserir a acessibilidade nas atividades, e contribuir para inclusão destas pessoas no turismo, com segurança e qualidade nos serviços prestados. As empresas precisam adaptar o que ofertam para torná-las acessíveis ou até mesmo elaborar seus produtos e desenvolver seus serviços com um padrão que possa ser usufruído por qualquer tipo de público, seja com deficiência, mobilidade reduzida, temporária ou permanente. Da mesma forma é essencial ter uma comunicação e informações direcionadas, e atendimento especializado e diferenciado para suprir às necessidades e anseios do público especial. Dessa forma, segundo Shimosakai, em entrevista concedida em 2011, "tornar acessível é dar oportunidade a todos" de realizar atividades turísticas.

\section{Legislação sobre a pessoa com deficiência}

Por meio da influência da "Declaração Universal dos Direitos Humanos" desenvolvida em 1948, uma das primeiras iniciativas legais que se destacou como um marco da defesa dos direitos das pessoas com deficiência foi a "Declaração dos Direitos das Pessoas Portadoras de Deficiência" em 1975, com a proposta de que os países que cooperassem com a Organização das Nações Unidas (ONU) deveriam adotar planos nacionais e internacionais para apoio e proteção das pessoas com deficiência. Na Declaração é citada a importância do direito de desfrutar da vida e realizar atividades sociais, culturais e recreativas.

As pessoas portadoras de deficiências, assiste o direito, inerente a todo e qualquer ser humano, de ser respeitado, sejam quais forem seus antecedentes, natureza e severidade de sua deficiência. Elas têm os mesmos direitos que os outros indivíduos da mesma idade, fato que implica desfrutar de vida decente, tão normal quanto possível (Artigo 3 - RESOLUÇÃO ONU 2.542/75 apud USP, 2014). 
Entre outros marcos, destacaram-se também as Convenções e Declarações internacionais que foram firmadas em encontros realizados pela Organização Internacional do Trabalho (OIT) e a ONU. A Carta para o Terceiro Milênio, aprovada em 1999, foi uma dessas iniciativas como forma de desenvolver ações que contribuíssem para a evolução das sociedades no que diz respeito à inclusão das pessoas com deficiência em todos os aspectos da vida (FADERS, 2011). Destacou-se da mesma forma o Programa de Ação Mundial para Pessoas Portadoras de Deficiência das Nações Unidas (ONU, 1982) que enfatiza que:

Os Estados Membros devem fazer com que as pessoas portadoras de deficiência tenham as mesmas oportunidades dos demais cidadãos para participarem de atividades de lazer. Isso supõe a possibilidade de utilizar restaurantes, cinemas, teatros, bibliotecas, etc., bem como locais de férias, estádios, hotéis, praias e outros locais de lazer. Os Estados Membros devem adotar medidas para eliminar todos os obstáculos neste sentido. As autoridades do setor turístico, as agências de viagem, os hotéis, as organizações voluntárias e outras entidades envolvidas na organização de atividades de lazer ou de oportunidades de viagem, devem oferecer os seus serviços a todos, sem discriminar as pessoas portadoras de deficiência. Isso implica, por exemplo, a inclusão de informações sobre acessibilidade na informação habitual que oferecem ao público (ONU, 1982).

Dessa forma, projetar a igualdade social pressupõe garantir a acessibilidade a todos, independentemente das diferenças, e entender a diversidade como regra e não com exceção (Mtur, 2006 ${ }^{4}$ ). No decorrer da história percebe-se uma mudança e evolução do conceito da deficiência, alterando-se cada vez mais o enfoque para a questão social, como é apresentado na Declaração de Madrid (2002), na qual se devem eliminar barreiras, promover ambientes acessíveis e elaborar políticas e normas sociais (FADERS, 2011).

No ano de 2006 ocorreu a Convenção sobre os Direitos das Pessoas com Deficiência, das Nações Unidas, na qual foi firmado um Protocolo Facultativo e os países signatários se comprometeram novamente a seguir os preceitos sobre os direitos das pessoas com deficiência em diversas áreas sociais (ONU, 2014). Assim, o turismo e o lazer acabam por ser inseridos entre estes aspectos de maneira abrangente, sendo um direito da pessoa com deficiência poder desfrutar de seus momentos de descanso, em atividades turísticas diversificadas e dispor de informações e produtos acessíveis.

No Brasil, as primeiras iniciativas voltadas para pessoas com deficiência ocorreram no Governo Imperial, com a criação do Instituto dos Meninos Cegos (atual Instituto Benjamin Constant) em 1854, e do Instituto dos Surdos-Mudos (atual Instituto Nacional de Educação de Surdos, INES), em 1857, ambos no Rio de Janeiro. Em 1874, foram criados centros especializados em deficiências mentais, como o Hospital Psiquiátrico da 
Bahia. No começo do século XX, foram criadas instituições filantrópicas, entre os quais a Sociedade Pestalozzi, em 1932. Nos anos 50 foi fundada a Associação de Pais e Amigos dos Excepcionais (APAE), e o Ministério da Educação e Cultura cria a Campanha Nacional de Educação e Reabilitação de Deficientes Visuais e Mentais (FERREIRA, 2002).

Entre outras medidas, a promulgação da Constituição Federal em 1988 forneceu as bases dos direitos das pessoas, inclusive com deficiência ou mobilidade reduzida e incentivou o início de novas ações. Assim, a Coordenadoria para Integração da Pessoa Portadora de Deficiência (CORDE), instituição autônoma, foi uma conquista que possibilitou a implantação em 1992 de uma Nova Política Nacional de Integração da Pessoa com Deficiência (Lei no 7.853, 1989), elaborando linhas de ação para fazer cumprir a obrigação do Estado e da Sociedade de proporcionarem atendimento aos cidadãos com deficiência (FERREIRA, 2002). Em 1999, foi feito um decreto que regulamenta a Lei no 7.853 , no qual segundo o Art.46, os órgãos e entidades da administração pública devem "estimular a ampliação do turismo à pessoa portadora de deficiência ou com mobilidade reduzida, mediante a oferta de instalações hoteleiras acessíveis e de serviços adaptados de transporte". Nesta seção V, Da Cultura, Do Desporto, Do Turismo e Do Lazer, trata-se desde o incentivo da realização de atividades até a necessidade de adaptação de instalações para recepcionar pessoas com deficiência (DECRETO № 3.298, DE 20 DE DEZEMBRO DE 1999).

Atualmente, as pessoas com deficiência contam com a presença de uma vasta legislação no âmbito municipal, estadual, federal e internacional, composta de leis, instruções normativas, decretos, além de leis complementares e resoluções que fornecem a base de direitos na área de educação, saúde, lazer e turismo, acessibilidade e demais setores presentes na sociedade.

No Brasil, a promoção de acessibilidade é obrigatória por lei e deve contemplar ações no que tange: aos espaços e edificações de uso público e coletivo; transporte; e informação e comunicação (endereços eletrônicos, telecomunicações, rádio e televisão, uso do sistema Braille e linguagem de Libras). No caso do setor de turismo, a intensidade de ações para o público especial foi maior após a criação do Ministério do Turismo que facilitou o desenvolvimento de uma política estrutural que tratasse sobre as pessoas com deficiência e mobilidade reduzida dentro do assunto de inclusão social.

As políticas de inclusão no turismo acabam por contribuir para a promoção e integração social. A pessoa com deficiência ou mobilidade reduzida é contemplada em legislações e referências normativas utilizadas na área de turismo que versam, principalmente, sobre seus direitos e a inclusão social, assim como a acessibilidade em espaços, equipamentos, serviços, atividades e informações turísticas.

Desde a Declaração Universal dos Direitos Humanos, de 1948, passando pela Constituição Federal, de 1988, continuando com o Programa Nacional dos Direitos Humanos, de 1996, e a Lei da Acessibilidade, de 19.12.2000, todos esses ditames, bem como seus desdobramentos e regulamentações, impõem que haja equidade de direitos e acessibilidade 
(ABNT, 2008). Dessa forma, as Normas Técnicas buscam fornecer diretrizes para orientar ações que promovam a acessibilidade em espaços, equipamentos, serviços, atividades e informações turísticas.

Como comentado anteriormente, uma das Normas Técnicas de maior destaque é a NBR 9050 (ABNT, 2004) que trata da acessibilidade efetiva em edificações, mobiliário, espaços e equipamentos urbanos. Todavia, enfatiza-se o fato de que apesar da existência de dois marcos legais em 1948 e 1975, de grande relevância mundial, entre outros, conforme citado anteriormente, foi somente a partir de 1997 que se desenvolveram as primeiras normas técnicas para a acessibilidade no Brasil. E a NBR 9050 (ABNT, 2004) prevê somente a acessibilidade urbana, não sendo ainda promovida em ambientes naturais e atividades de ecoturismo e turismo de aventura.

Em âmbito internacional,

desde 1992 existem as Normas ISO (Organização Internacional de Normalização ${ }^{5}$ ) e comitês técnicos para ajudas técnicas, transporte, edificações e mobilidade adequados a pessoas com deficiência. A Comissão Panamericana de Normas Técnicas (COPANT ${ }^{6}$ ) em 1996 tinha sete normas aprovadas relativas à acessibilidade ao meio físico e quatro anteprojetos em andamento (ARIAS, 2008 p.45).

Segundo a autora Arias, os primeiros países a elaborarem Normas e Legislação para o tema de acessibilidade foram os Estados Unidos, Canadá, Japão, Alemanha e Reino Unido.

Conforme o referencial teórico, as primeiras Normas e Legislações sobre o tema de acessibilidade foram elaboradas a partir da década de 1940. Atualmente no século XXI, há uma nova compreensão social da deficiência e da acessibilidade, pois foram criadas leis que punem a discriminação, protegem os direitos das pessoas com deficiência ou mobilidade reduzida, estimulam as ações voluntárias a seu favor e das entidades que delas cuidam, e fornecem orientações para a acessibilidade. Existem centenas de entidades que congregam pessoas com deficiência, que se organizam para lutar por seus direitos e pela criação de novas oportunidades de trabalho.

Porém, são as próprias pessoas com deficiência que precisam fazer parte deste processo de maneira efetiva, pois de nada vale a existência de leis se não forem cumpridas e exigidas por quem mais depende delas. $O$ destaque de ações nos anos 1990 e 2000 mostram que a sociedade está se conscientizando e compreendendo os problemas que a permeiam, realizando novas ações e desenvolvendo novas políticas de incentivo à inclusão social. No turismo, a inclusão se dá pela possibilidade de desfrute por pessoas com deficiência ou mobilidade reduzida de atividades variadas, inclusive de ecoturismo e turismo de aventura, proporcionando o prazer de viver bem e feliz com melhores condições de vida. 


\section{Resultados e discussões}

Os resultados obtidos em pesquisa qualitativa com as empresas dos segmentos de ecoturismo e turismo de aventura são apresentados a seguir segmentados em duas partes distintas. Os assuntos são sempre tratados de forma a dialogar com o referencial teórico e são incluídos depoimentos de empresários no decorrer das exposições, mantendo-se o anonimato dos respondentes (as empresas são somente identificadas por números na ordem de recebimento de respostas).

Em primeiro lugar são destacadas as iniciativas que devem ser de responsabilidade do poder público e seu papel para desenvolvimento das atividades de ecoturismo e turismo de aventura de forma acessível sob a ótica das empresas respondentes. Em seguida, aborda-se o papel do empreendedor na elaboração de roteiros e produtos acessíveis, enfatizando a importância da inclusão social, e também sob a ótica das empresas, a oportunidade que o público especial oferece para ampliação de negócios.

\section{Acessibilidade e Turismo: iniciativas e o papel do poder público}

O poder público, no que diz respeito ao setor de turismo no Brasil, tem como importante papel delinear políticas públicas, incentivar empresas, fomentar e promover o desenvolvimento turístico. No país essas ações foram fortalecidas no âmbito do turismo a partir da criação do Ministério do Turismo em 2003, momento em que houve uma estruturação e presença de orçamentos definidos para o setor. Entretanto até os dias atuais a área de turismo ainda não é considerada prioridade no que tange às políticas públicas (BENI, 2006), sendo a situação ainda mais problemática quando se trata da acessibilidade nos segmentos de turismo De acordo com Marques (1977 apud BENI, 2006, p.17),

toda política pública é concebida a partir de uma representação do setor à qual ela se refere, assim como a um conjunto de normas, organizações, técnicas e recursos de poder que a implementarão. Por conseguinte, é necessário, ao proceder à análise de políticas, que se procure integrar a dimensão da representação às práticas que se inter-relacionam e contemplar três elementos fundamentais: a relação global-setorial, o referencial do setor e os mediadores da política.

O autor faz alusão à necessidade de haver uma integração entre os setores e o governo de forma geral para que a política pública tenha uma representatividade e seja de utilidade para o setor e pessoas envolvidas no processo. Em assuntos relacionados à acessibilidade é necessário muita atenção ao que se produz de ações governamentais, observando a utilidade de tais fatores para a melhoria da acessibilidade, tanto em setores específicos como o turismo, quanto na sociedade de maneira geral.

Entre as empresas participantes da pesquisa, questionadas sobre o papel do poder público com relação à acessibilidade no ecoturismo e 
turismo de aventura, o que mais foi citado é a necessidade de investimentos para o desenvolvimento e a viabilização da infraestrutura básica dos municípios e mínima para os turistas, bem como capacitação de profissionais, contribuindo para o melhor acesso de turistas aos atrativos, assim como dos próprios moradores, culminando com um maior estímulo à visitação turística. Dentre as empresas respondentes, pode-se destacar a seguir o depoimento de dois empresários.

Possibilitar que o maior número de pessoas visite o destino, bem como tenha acesso aos atrativos turísticos de forma igualitária, se sinta integrada e, principalmente, respeitada (Empresa 16, Ilhéus/BA).

Ainda há muito que ser feito a esse respeito, tanto no setor público quanto no privado. Falta especialização, padronização e acima de tudo vontade de fazer bem e bem feito (Empresa 12, Brotas/SP).

Dentre os demais papéis citados para cumprimento do poder público está a possibilidade de fornecer incentivos às empresas interessadas, seja por dedução de impostos, linhas específicas de financiamento, projetos, programas e campanhas direcionadas, bem como se deve facilitar a aquisição de equipamentos técnicos de aventura com preços menores e dar apoio técnico na melhoria da infraestrutura turística, auxiliando nas adaptações, na formalização e padronização de serviços. Nas palavras de um dos entrevistados, o poder público, da mesma forma que as empresas, deve mostrar "responsabilidade e compromisso com os serviços oferecidos" e "desempenhar um papel social, ajudando na inclusão" (Empresa 18, Manaus/AM). Acima de tudo, o governo deve incrementar as regiões turísticas, contribuir com o processo de normalização e fomentar 0 desenvolvimento da acessibilidade no turismo.

O termo "inclusão" pode ser interpretado como a participação e presença do público especial no setor de turismo e está diretamente relacionado ao conceito de turismo social que pode ser definido, de acordo com a Organização Internacional de Turismo Social (OITS, 2012) como: "um conjunto de relações e fenômenos que resultam da participação em turismo e, em particular, da participação de camadas sociais menos favorecidas". Todavia Jolin (OITS, 2012) se refere a algo mais amplo conforme se observa a seguir:

a programas, realizações e ações que pretendem efetivar o direito às férias e a acessibilidade no turismo a todos os grupos populacionais, em particular jovens, famílias, pessoas com deficiência ou mobilidade reduzida, mas que também pretende alcançar uma qualidade na relação entre visitantes e comunidades anfitriãs (JOLIN apud OITS, 2012, s/p, tradução nossa). 
A "nuvem" de palavras apresentada a seguir (Figura 1) enfatiza os principais termos utilizados pelas empresas respondentes da pesquisa para definir o papel do poder público no que diz respeito à acessibilidade. As palavras intensificadas em maior proporção destacam a maior frequência de citações em que elas apareceram. Neste caso, destaca-se que é necessário que o governo contribua para a melhoria da acessibilidade urbana e dos espaços públicos, fomentando e implementando estruturas acessíveis, assim como precisa facilitar as condições de locomoção por pessoas com deficiência ou mobilidade reduzida.

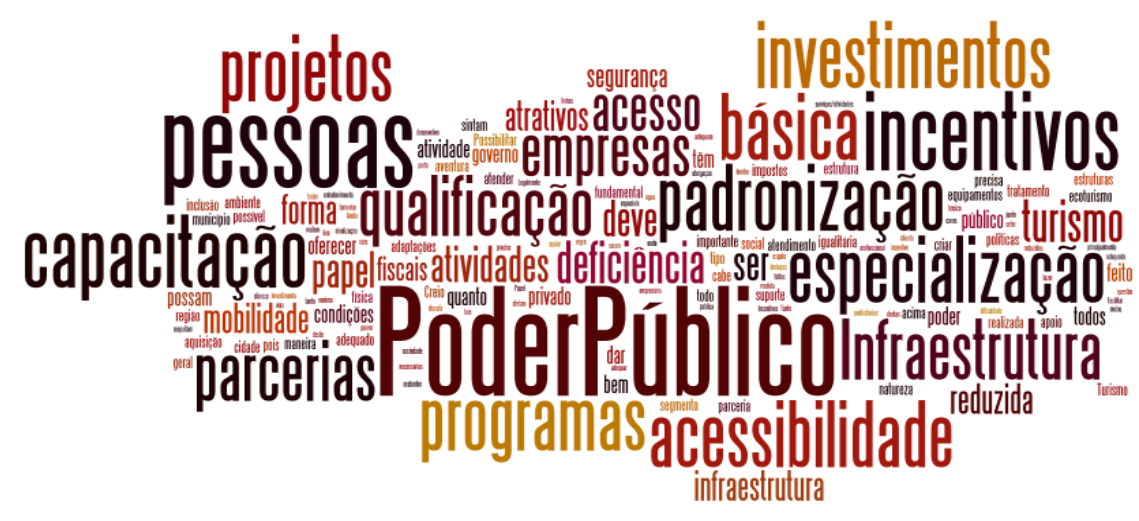

Figura 1: Nuvem de palavras - principais termos destacados pelas empresas sobre 0 poder público. Fonte: elaborado pelos autores

Figure 1: Word cloud - top terms highlighted by companies about government.

Source: elaborated by authors.

Em um dos depoimentos (empresa 19, Lençóis/BA), o entrevistado afirmou que a acessibilidade é fundamental, mas ainda é um sonho sua empresa poder trabalhar com o público especial, pois sua cidade não oferece estrutura para essas pessoas se locomoverem e afirma que as prefeituras da Bahia não respeitam a lei da acessibilidade - em referência à norma ABNT NBR 9050 (ABNT, 2004), citada anteriormente.

Por fim, em outro depoimento (empresa 20, Campinas/SP), outro entrevistado afirma que o poder público tem a obrigação de "garantir de forma segura e correta a acessibilidade para pessoas com deficiência ou mobilidade reduzida", que têm "o direito básico de ir e vir com segurança, independente do ambiente em que estejam", tendo uma das empresas criticado o poder público por ainda dar pouca importância para o setor de turismo.

Dessa forma, é necessária a celebração de parceria público-privada para "conscientizar e subsidiar ações de acessibilidade" (empresa 47, Fortaleza/CE), favorecendo o aumento de investimentos para os segmentos de ecoturismo e turismo de aventura, o que contribui para a promoção e divulgação das empresas e destinos turísticos, além de a acessibilidade significar um retorno financeiro relevante para os atores e regiões turísticas envolvidas. 


\section{Acessibilidade: oportunidades de negócio e o papel do empreendedor}

O mercado de ecoturismo e turismo de aventura por si só apresenta um potencial de crescimento no Brasil, em decorrência da valorização e melhor aproveitamento dos espaços naturais. A acessibilidade torna-se assim uma oportunidade de negócio para as empresas destes segmentos, alavancando seu crescimento, diversificando produtos e serviços, e favorecendo o acesso ao turismo para um número maior de indivíduos e à inclusão social.

Segundo o Relatório de Impactos do Programa Aventura Segura (ABETA/MTUR, 2011), as empresas desses segmentos são, em sua maioria, de micro e pequeno porte. Muitas são administradas por empreendedores que se dispuseram a arriscar e inovar, desenvolvendo novos produtos e serviços para os turistas. $O$ papel desses empreendedores e outros que estejam dispostos a entrar para o mercado é ter visão de longo prazo, buscar parcerias duradouras com outras empresas e com o poder público. Deve saber ainda aproveitar e cobrar os incentivos públicos, cursos de capacitação e buscar outros tipos de suportes para conseguir aprimorar seus negócios.

Além disso, é essencial que as empresas tenham inerente aos seus negócios a responsabilidade social corporativa o que, de acordo com 0 World Business Council for Sustainable Development (WBCSD apud BENI, 2006, p.39), é definido como:

Um comprometimento contínuo das empresas de agir eticamente e contribuir para o desenvolvimento econômico enquanto melhoram a qualidade de vida de seus colaboradores e familiares, assim como da comunidade local e da sociedade como um todo.

E para alcançar tais responsabilidades, segundo Beni (2006, p.39) é necessário que a empresa conheça bem seus stakeholders, o que é definido pelo autor como sendo "pessoas que estão ligadas a uma organização, ou que apresentam interesses em uma organização, e que são afetadas pelas decisões tomadas por essa organização", como por exemplo, os colaboradores, órgãos governamentais e comunidades. A partir desse entendimento de responsabilidade socioambiental é possível se estabelecer uma relação eficaz também com clientes, o que no caso do público especial é totalmente necessário e essencial.

Para se ter uma ideia das áreas de atuação das empresas de ecoturismo e turismo de aventura presentes no mercado brasileiro foi realizada uma pesquisa com membros da ABETA, conforme citado anteriormente. As organizações que responderam à pesquisa foram classificadas de acordo com a sua atuação no mercado conforme se observa no Gráfico 1. Percebe-se pela abrangência de respostas que as empresas não apresentam apenas uma área de atuação, sendo que as empresas que prestam consultoria (10,6\%), por exemplo, também podem ser operadora turística, receptivo, atrativo organizado, entre outros. 


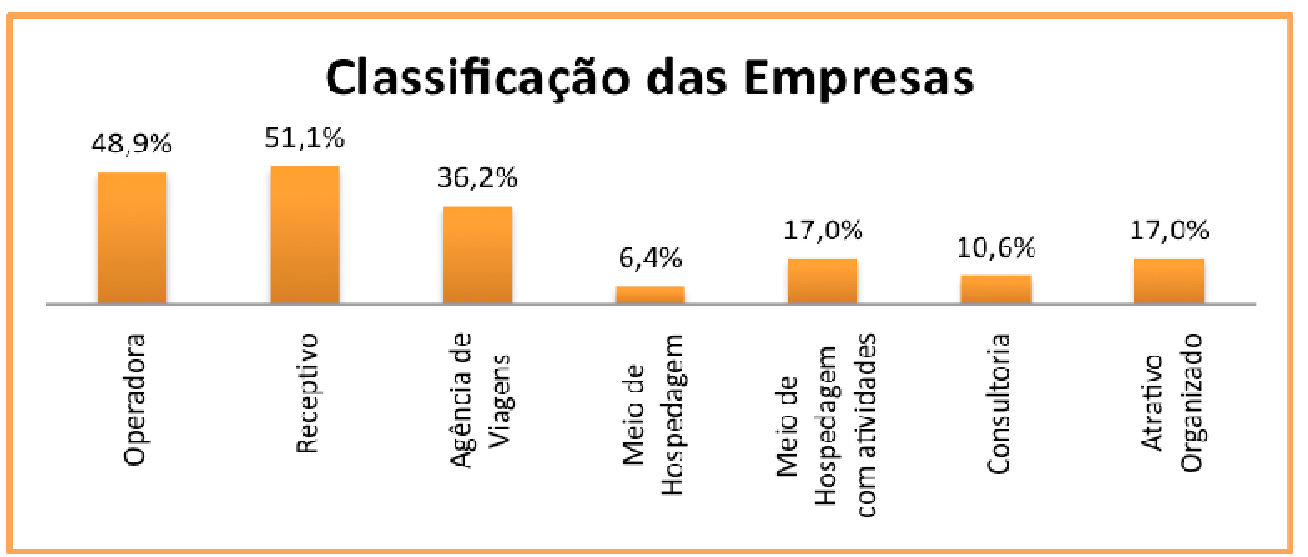

Gráfico 1: Classificação das empresas de ecoturismo e turismo de aventura

Fonte: elaborado pelos autores

Graphic 1: Classification of ecotourism and adventure tourism companies

Source: elaborated by authors.

O tempo de atuação nos segmentos de ecoturismo e turismo de aventura varia muito de empresa para empresa (Gráfico 2), sendo que a maior parte (45\%) atua no mercado a mais de 10 anos, 26\% atua de 2 a 5 anos, e $23 \%$ das empresas estão no mercado entre 6 a 10 anos. Apenas $6 \%$ dos entrevistados estão no mercado a menos de 2 anos. Os dados mostram que a maior parcela dos respondentes são empresas que já estão no mercado há muito tempo.

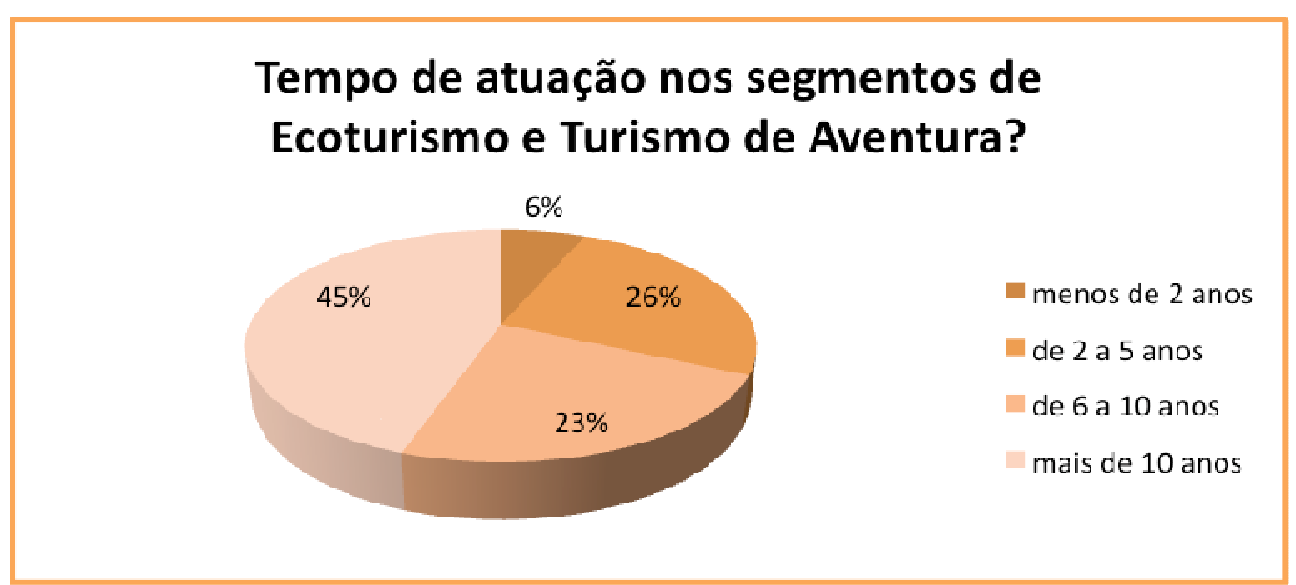

Gráfico 2: Tempo de atuação das empresas nos segmentos de ecoturismo e turismo de aventura. Fonte: elaborado pelos autores

Graphic 2: Performance's time of companies in the segments of ecotourism and adventure tourism. Source: elaborated by authors.

Entre as empresas entrevistadas, foi feita uma consulta sobre os tipos de atividades ofertadas em seus destinos de atuação (Gráfico 3). Cerca de $66 \%$ dos respondentes oferecem atividades de caminhada de curto e longo curso, $42,6 \%$ oferecem atividades de rapel, $34 \%$ oferecem a atividade de observação da vida silvestre (também conhecida como birdwatching) e 31,9\% oferecem atividades de arvorismo, tirolesa e 
escalada. Dentre as empresas, 23,4\% afirmaram oferecer também outras atividades não expostas no gráfico 3, tais como: windsurfing, kitesurfing, sandboarding, vôo de parasail, floating ou mini rafting, e corrida de aventura.

Segundo os entrevistados, as atividades com maior frequência oferecidas pelas empresas são as mais consolidadas no mercado e as que os clientes mais procuram. $\mathrm{E}$ as atividades como caminhada e observação da natureza, como muitas vezes não apresentam custos elevados para implantação são ofertadas pela maioria das empresas.



Gráfico 3: Tipos de atividades oferecidas pelas empresas

Fonte: elaborado pelos autores

Graphic 3: Types of activities offered by companies

Source: elaborated by authors.

Tratando da temática específica de acessibilidade, as empresas foram indagadas quanto a ter algum produto e/ou serviço para pessoas com deficiência ou mobilidade reduzida (Gráfico 4). Destas, apenas 48,9\% disseram que possuem produtos e/ou serviços para pessoas com deficiência ou mobilidade reduzida, e as $51,1 \%$ restantes disseram não apresentar nenhum tipo. É interessante ressaltar que das 48,9\% empresas com algum tipo de acessibilidade em suas atividades, $25,5 \%$ são as empresas que atuam no mercado a mais de 10 anos. Isto pode significar que o tempo de atuação no mercado está diretamente relacionado à experiência da empresa e sua percepção das necessidades de adaptação ao mercado e aos diferentes perfis de públicos existentes. 


\section{Produtos e/ou Serviços para o Público Especial}

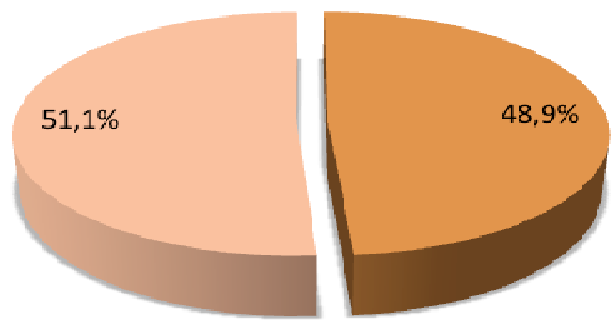

- Sim

Não

Gráfico 4: Porcentagem das empresas que apresentam produtos e/ou serviços para o público especial. Fonte: elaborado pelos autores

Graphic 4: Percentage of companies that have products and/or services to special public

Source: elaborated by authors.

Para compreender quais são os tipos de produtos e serviços oferecidos pelas empresas, estas foram questionadas sobre as estratégias utilizadas para atendimento ao público especial (Gráfico 5). Dentre as 48,9\% empresas que disseram possuir algum tipo de produto e/ou serviço acessível, 78,3\% apresentam, como estratégia para 0 atendimento alguns procedimentos operacionais diferenciados. Além disso, 60,9\% destas empresas também oferecem serviços e/ou roteiros adaptados e 39,1\% possuem acessibilidade física, bem como realizam capacitação e treinamento dos colaboradores. Uma das empresas entrevistadas, apesar de ter considerado que apresenta produtos e/ou serviços para o público especial, na verdade possui algum tipo de adaptação somente para pessoas com mobilidade reduzida.



Gráfico 5: Estratégias para atendimento ao turista com deficiência ou mobilidade reduzida. Fonte: elaborado pelos autores

Graphic 5: Strategies to support the tourist with a disability or reduced mobility

Source: elaborated by authors.

Das $51,1 \%$ empresas que não possuem nenhum tipo de produto e/ou serviços acessíveis (Gráfico 4), de acordo com o Gráfico 6, cerca de 41\% apresentaram como motivo para a não implantação da acessibilidade 0 
custo elevado em materiais, equipamentos e tecnologias, seguido pelo custo elevado em treinamento de pessoal $(18,1 \%)$. O fato de não haver vantagem financeira e nem reconhecimento dos clientes foi assinalado por $4,5 \%$ das empresas. Outros motivos para a não implantação da acessibilidade é que, apesar de existirem projetos, estes ainda não foram colocados em prática por algumas empresas por questões de priorização de assuntos mais urgentes para investimento, como é o caso de uma empresa de São Luiz do Paraitinga que foi prejudicada em decorrência das enchentes que provocaram danos na cidade em 2010.

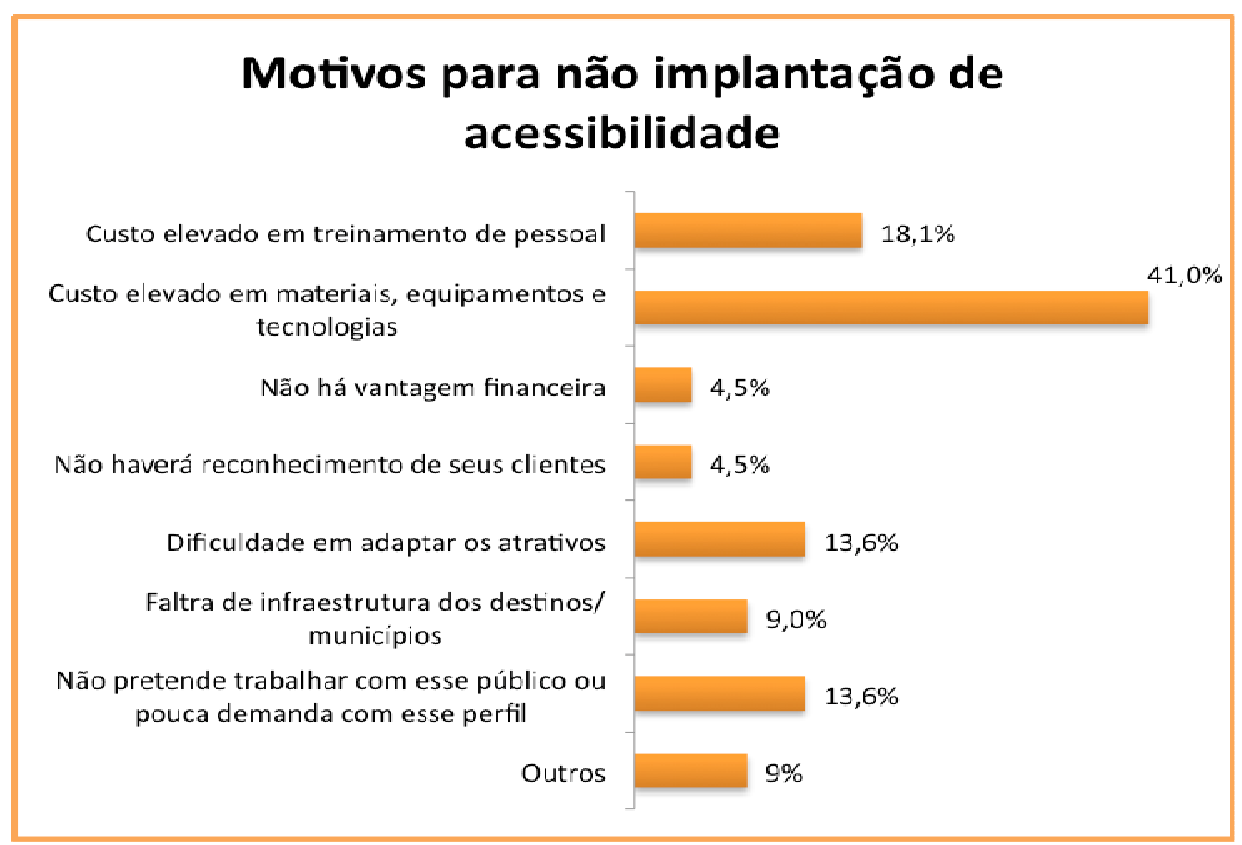

Gráfico 6: Motivos para a não implantação da acessibilidade nas empresas Fonte: elaborado pelos autores

Graphic 6: Reasons for non-implementation of accessibility in businesses Source: elaborated by authors.

Ainda de acordo com as empresas que não apresentam nenhum tipo de ação em relação à acessibilidade (Gráfico 7 ), $83 \%$ se mostraram dispostas e interessadas em adotar a acessibilidade em suas atividades, equipamentos e serviços turísticos. Um dos motivos para tal interesse é aumentar o conjunto de opções e serviços adaptados para públicos distintos. Entretanto, 17\% ainda não se mostram interessadas e dispostas a adotar medidas para acessibilidade, devido aos vários fatores apresentados anteriormente, principalmente, referente às questões de ordem financeira e dificuldades que existem para adaptar alguns espaços e atividades de ecoturismo e aventura.

Todas as empresas participantes da pesquisa consideram a existência de acessibilidade nos segmentos de ecoturismo e turismo de aventura importante e necessária, pois as atividades oferecidas contribuem para a qualidade de vida e bem estar do público especial. Entretanto, uma das ressalvas foi que apesar de ser importante, a acessibilidade somente é viável em locais que permitam tais adaptações. 


\section{Disposição em adotar a acessibilidade}

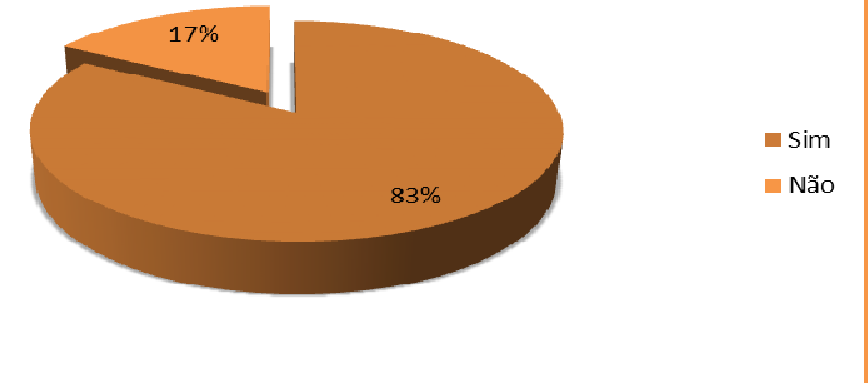

Gráfico 7: Interesse das empresas em adotar a acessibilidade Fonte: elaborado pelos autores

Graphic 7: Interest of companies to adopt accessibility Source: elaborated by authors.

Quando indagadas sobre qual deve ser o papel das empresas com relação à acessibilidade no ecoturismo e turismo de aventura, as principais respostas obtidas mostram que é possível e viável as empresas adaptarem seus procedimentos e serviços para receber pessoas com deficiência ou mobilidade reduzida, na medida em que existam incentivos públicos. Um dos entrevistados defende que as empresas devem ser responsáveis pela acessibilidade dentro de sua área de atuação e outro acrescenta que é preciso se adaptar às exigências legais. Dessa forma, o poder público pode fornecer incentivos, mas as empresas precisam cumprir com suas responsabilidades sociais.

Também, as empresas precisam investir na adaptação de sua própria infraestrutura, seja nos atrativos turísticos particulares, em destinos e/ou locais de atendimento ao turista, contribuindo para o aumento da demanda, e a capacitação e treinamento adequado dos diversos colaboradores, principalmente, condutores para disponibilizar "um produto de qualidade, com conforto, seguindo as normas e visando a segurança nas atividades" (empresa 30, Socorro/SP).

$\mathrm{Na}$ "nuvem" de palavras (Figura 2) a seguir são apresentados os principais termos relacionados ao universo das empresas pesquisadas. Conforme uma das empresas (empresa 30, Socorro/SP), os segmentos de ecoturismo e turismo de aventura estão se adaptando ao público especial há algum tempo e um exemplo disso é um empreendimento de aventura, localizado no município de Socorro. Porém a empresa afirma que há outros parques de aventura totalmente estruturados e adaptados para receber este público, fato que não foi exatamente constatado em pesquisa desenvolvida em fontes secundárias e nem confirmado pelas outras empresas em outros Estados.

Todavia, também é enfatizado pelo respondente os grandes benefícios das atividades desses segmentos, sendo que a adaptação pode significar retorno positivo a longo prazo, e que as empresas precisam enxergar o público especial como demanda potencial, buscando uma troca de valores e experiências entre cliente e empresa. Outra entrevistada vai mais além ao sugerir que as empresas elaborem e adaptem pelo menos 
$10 \%$ de seus produtos para o público especial (empresa 9, Rio de Janeiro/RJ).

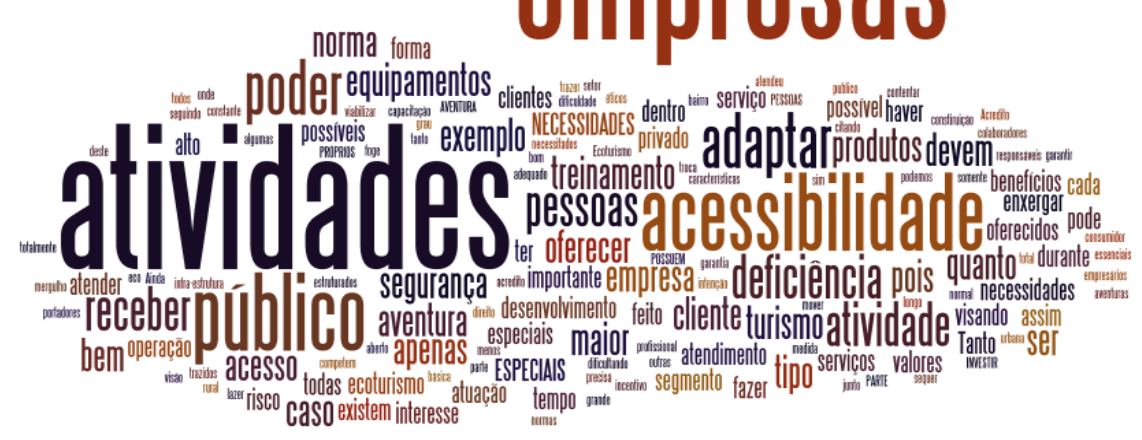

Figura 2: Nuvem de palavras - principais termos destacados pelas empresas

Fonte: elaborado pelos autores

Figure 2: Word cloud - top terms highlighted by companies

Source: elaborated by authors.

Outra questão que foi levantada entre os entrevistados é que nem todas as atividades apresentam viabilidade de adaptação, devido aos riscos inerentes e, com as que apresentam mesmo assim se tem dificuldade, pois às vezes é necessário adaptar serviços e atividades de ecoturismo e turismo de aventura para um público especial ao mesmo tempo em que se atende um público que não necessita de atendimento personalizado e acessibilidade. Segundo as respostas obtidas, a empresa interessada em atender esse público especial precisa fazer uma análise de quais são os produtos de ecoturismo e aventura que podem ser oferecidos de maneira acessível e disponibilizados às pessoas com deficiência ou mobilidade reduzida. Em muitos casos é preciso observar o tipo de deficiência da pessoa e tecnicamente criar estrutura para tal atendimento.

Dessa forma, as empresas que não possuem essa preocupação deixam de cumprir com a responsabilidade social, com o papel de detentora de atendimento de qualidade e podem prejudicar seus negócios, perdendo credibilidade no mercado, na medida em que oferecem produtos, serviços e atendimento inadequado para esse público. Fato de grande relevância é a presença de profissionais qualificados e capacitados para realizar o atendimento do público especial de maneira adequada. Sendo assim, é necessário que exista um espaço de discussão e formação para esses profissionais que irão compor o mercado.

\section{Considerações finais}

O estudo fundamentou-se no universo da acessibilidade inserido nos segmentos de ecoturismo e turismo de aventura, sendo que a discussão estava relacionada à questão dos segmentos estarem acessíveis para atender o público especial. Percebe-se que para que um produto, serviço ou 
destino turístico esteja preparado para atender o público especial, é necessário que exista uma atuação conjunta do poder público e das empresas de ecoturismo e turismo de aventura.

A partir dos resultados da pesquisa com as empresas, conclui-se que não há como afirmar que grande parte do mercado esteja preocupada com a temática, porém há como concluir que uma amostra de empresas que são consideradas exemplos no mercado podem influenciar as demais e ditar tendências. Assim, as empresas dos segmentos tendem a buscar certificações, adequar serviços e oferecer produtos com melhor qualidade e acessibilidade. Acrescenta-se como fator positivo a mobilização do poder público, por meio do Ministério do Turismo, em realizar parcerias e elaborar cartilhas e manuais de apoio às empresas. Entretanto, a acessibilidade ainda é abordada de maneira superficial nas publicações. A disposição efetiva do poder público poderia significar ajuda por meio de incentivos e investimentos no setor de turismo, hoje ações incipientes, fato que influencia muitos empresários a não implantar acessibilidade em seus negócios.

Com relação ao papel e integração do poder público e privado, constata-se pela pesquisa que no Brasil ainda é preciso estruturar melhor a relação que se estabelece entre esses atores. Ao poder público compete, como visto, facilitar o acesso das empresas a investimentos e incentivos para adaptação de suas infraestruturas, equipamentos, atividades e serviços, além de fomentar o turismo, elaborar políticas públicas, fiscalizar e exigir o cumprimento da legislação sobre a acessibilidade nos espaços públicos. Qualquer turista que visita um atrativo turístico necessita da infraestrutura básica dos municípios e orientações/informações turísticas adequadas, principalmente o público especial, o que ainda falta em muitas destinações turísticas. Às empresas cabe o papel de empreender, buscar novos conhecimentos, se atualizar constantemente, estruturar a organização e formatar produtos/roteiros que possam ser realizados pelo público especial, assim como adequar seus procedimentos operacionais, saber realizar um atendimento personalizado e estabelecer comunicação adequada com os turistas, independente de serem pessoas sem ou com deficiência ou mobilidade reduzida.

\section{Referências bibliográficas}

ABETA - ASSOCIAÇÃO BRASILEIRA DAS EMPRESAS DE ECOTURISMO E TURISMO DE AVENTURA. 2011. Associados da Abeta. Disponível em: <www.abeta.com.br>. Acesso em: 30 de março de 2014.

ABNT - ASSOCIAÇÃO BRASILEIRA DE NORMAS TÉCNICAS. NBR 15599/08: Acessibilidade - comunicação na prestação de serviços. Rio de Janeiro: $\quad$ ABNT, 2008. Disponível em: $<$ http://portal.mi.gov.br/corde/arquivos/ABNT/NBR15599.pdf>. Acesso em: 14 de agosto de 2011.

ABNT - ASSOCIAÇÃO BRASILEIRA DE NORMAS TÉCNICAS. NBR 9050/04: Acessibilidade a edificações, mobiliário, espaços e equipamentos urbanos. Rio de Janeiro: ABNT, 2004. Disponível em: < http://www.mpdft.gov.br/sicorde/NBR9050-31052004.pdf>. Acesso em: 14 de agosto de 2011. 
ARIAS, C.R. A arquitetura como instrumento do projeto inclusivo: percepção do surdocego. Campinas, SP: [s.n.], 2008. Tese (Doutorado) - Universidade Estadual de Campinas, Faculdade de Engenharia Civil, Arquitetura e Urbanismo, 2008.

BENI, M.C. Política e Planejamento de Turismo no Brasil. São Paulo: Aleph, 2006 - (Série turismo).

BRASIL, ABETA e Ministério do Turismo - MTUR. Relatório de Impactos do Programa Aventura Segura. Belo Horizonte: Ed. dos autores, 2011, 166 p. Série Aventura Segura.

BRASIL, Ministério do Turismo. Turismo e Acessibilidade: manual de orientações. 2a Ed. Brasília: Ministério do Turismo, 2006. 294 p. Coordenação Geral de Segmentação.

BRASIL. Decreto № 3.298, de 20 de Dezembro de 1999. Dispõe sobre a Política Nacional para a Integração da Pessoa Portadora de Deficiência, consolida as normas de proteção, e dá outras providências. Disponível em: $<$ http://www.planalto.gov.br/ccivil 03/decreto/d3298.htm>. Acesso em: 30 de março de 2014.

COMISSÃO PANAMERICANA DE NORMAS TÉCNICAS - COPANT. Disponível em: <www.copant.org >. Acesso em: 06 de abril de 2014.

FADERS - FUNDAÇÃO DE ARTICULAÇÃO E DESENVOLVIMENTO DE POLÍTICAS PÚBLICAS PARA PPDS E PPAHS. Legislação Internacional. 2011. Disponível em: <www.portaldeacessibilidade.rs.gov.br/>. Acesso em: 02 de setembro de 2011.

FERREIRA, E.L. Dança em cadeiras de rodas: os sentidos dos movimentos na dança como linguagem não verbal. Brasília: Publicações SNE, 2002. Instituto Nacional de Desenvolvimento do Desporto. Série Esportes para pessoas portadoras de deficiência.

IBGE - INSTITUTO BRASILEIRO DE GEOGRAFIA E ESTATÍSTICA. Censo Demográfico de 2010. Disponível em: <http://www.ibge.gov.br>. Acesso em: 30 de março de 2014.

MOREIRA, D. Turismo de aventura especial: como atender a pessoa com deficiência. 2 ${ }^{\mathrm{a}}$ ed. São Paulo, 2010.

OITS - ORGANIZAÇÃO INTERNACIONAL DO TURISMO SOCIAL. Conceptos y definiciones. Disponível em: < www.bits-int.org $>$. Acesso em: maio de 2012.

ONU - ORGANIZAÇÃO DAS NAÇÕES UNIDAS. A ONU e as pessoas com deficiência. Disponível em: < http://www.onu.org.br/a-onu-em-acao/a-onue-as-pessoas-com-deficiencia/>. Acesso em: 30 de março de 2014.

ONU - ORGANIZAÇÃO DAS NAÇÕES UNIDAS. Programa de Ação Mundial para as Pessoas com Deficiência, 1982. Disponível em: <www.mpdft.gov.br/ >. Acesso em: 24 de julho de 2011.

ORGANIZAÇÃO INTERNACIONAL DE NORMALIZAÇÃO - ISO. Disponível em: <www.iso.org $>$. Acesso em: 06 de abril de 2014. 
SILVA, G.G.L. Acessibilidade no Ecoturismo e Turismo de Aventura: uma análise do mercado, público especial e atores envolvidos. 2011. Monografia - Escola de Comunicações e Artes, Universidade de São Paulo, São Paulo, 2010.

USP - UNIVERSIDADE DE SÂO PAULO. Declaração de Direitos das Pessoas Deficientes - 1975. Biblioteca Virtual de Direitos Humanos, 2014. Disponível em: < http://www.direitoshumanos.usp.br/ >. Acesso em: 30 de março de 2014.

VIVARTA, Veet (org.). Mídia e Deficiência. Brasília: Andi; Fundação Banco do Brasil, 2003. 184 p.; il. color. Série Diversidade. Disponível em: $<$ http://www.andi.org.br/inclusao-e-sustentabilidade/publicacao/midia-edeficiencia $>$. Acesso em: 4 de setembro de 2011.

\section{Notas:}

1 Este artigo foi inicialmente apresentado pelos autores no XII Encontro Nacional de Turismo com Base Local (ENTBL), realizado em São Paulo (SP), no período de 06 a 08 de novembro de 2012, e revisado para publicação. O tema é baseado em um trabalho de conclusão do curso de turismo da ECA (USP).

2 A Associação Brasileira das Empresas de Ecoturismo e Turismo de Aventura (ABETA) possui como principais objetivos representar, qualificar e promover seus associados que são mais de 180 empresas com sede em todo país. A Associação atua na defesa dos interesses dos associados junto ao mercado, poder público e privado com a proposta de torná-los agentes atuantes nos segmentos de ecoturismo e turismo de aventura, priorizando alternativas sustentáveis e desenvolvendo os destinos e comunidades locais. Disponível em: < http://abeta.tur.br/>. Acesso em: 27 de março de 2014.

${ }^{3}$ Elemento: qualquer dispositivo de comando, acionamento, comutação ou comunicação. São exemplos de elementos: telefones, intercomunicadores, interruptores, torneiras, registros, válvulas, botoeiras, painéis de comando, entre outros (ABNT, 2004).

4 Promoção da Acessibilidade em Equipamentos, Atrativos e Serviços Turísticos. In: Turismo e Acessibilidade: manual de orientações, Mtur, 2006.

5 A Organização Internacional de Normalização (ISO) é o maior órgão mundial na elaboração e publicação de Normas Internacionais. É uma organização não governamental e é constituída por 146 países membros. Disponível em: <www.iso.org >. Acesso em: 30 de março de 2014.

${ }^{6}$ A Comissão Panamericana de Normas Técnicas é uma organização não governamental, organismo regional de normalização das Américas, abrangendo 25 países membros ativos e 9 apoiadores da América do Sul, Central, Norte e Caribe, desde o Canadá e os EUA até a Argentina e o Chile. Disponível em: <www.copant.org>. Acesso em: 30 de março de 2014. 
Grislayne Guedes Lopes da Silva: Universidade de São Paulo, São Paulo, SP, Brasil.

E-mail: grislayne.silva@usp.br

Link para o currículo Lattes: http://lattes.cnpq.br/1473848485735432

Reinaldo Miranda de Sá Teles: Universidade de São Paulo, São Paulo, SP, Brasil.

E-mail: reiteles@usp.br

Link para o currículo Lattes: http://lattes.cnpq.br/5662794770689990

Data de submissão: 30 de junho de 2012

Data de recebimento de correções: 19 de abril de 2014

Data do aceite: 28 de abril de 2014

Avaliado anonimamente 